\title{
La reforma laboral de 2012: descodificando reformas del anterior Gobierno, intentando implementar la extravagante flexiseguridad. ¿Qué hay de nuevo?
}

\author{
Francisco Javier Arrieta Idiakez \\ Profesor de Derecho del Trabajo. Universidad de Deusto
}

Recibido: 14.05 .2012

Aceptado: 31.05.2012

\begin{abstract}
Resumen: Nuevo Gobierno, nueva reforma laboral. Y en este caso descodificando las ineficaces, tortuosas e incomprensibles reformas del anterior Gobierno. Así se deduce de la Exposición de Motivos del Real Decreto-ley 3/2012, de 12 de febrero, de medidas urgentes para la reforma del mercado laboral. En concreto, en relación con la Seguridad Social, se está produciendo el fenómeno de «quita y no pon se acaba el montón», pues coinciden en el tiempo el descenso de afiliados/cotizantes y el aumento de desempleados y jubilados, a lo que hay que sumar el envejecimiento de nuestra sociedad y el aumento, a futuro, del gasto sanitario. A todo ello pretende enfrentarse la nueva reforma laboral. Y según se deduce, nuevamente, de la Exposición de Motivos del Real Decreto-ley 3/2012, no porque nuestros gobernantes se hayan percatado de esta situación, sino porque parece que todas las instituciones económicas mundiales y europeas conocen mejor lo que sucede en el mercado laboral español. Pero el nuevo Gobierno promete ser obediente y aplicar la fórmula propuesta por dichos agentes internacionales para salir de esta crisis, para solucionar todos los problemas mencionados: la flexiseguridad. ¿Qué hay de nuevo?
\end{abstract}

Palabras clave: Reforma laboral de 2012, flexiseguridad, medidas para favorecer la empleabilidad, fomento de la contratación indefinida, flexibilidad interna y externa.

Summary: A new government, and new labour reform. In this case, decoding the inefficient, tortuous and incomprehensible reforms of the previous government is needed. This is clear from reading the Explanatory Memorandum to Royal Decree Law 3/2012 of 12 February, on urgent measures to reform the labour market. Specifically, with regards to the Social Security System, the phenomenon of being unable to "save something for a rainy day" is becoming ever present on a day to day basis, given the decline in numbers of contributors, and the increase in unemployed and retired individuals. To this we must add, our society's increased life expectancy, and the rising expense of funding our health care systems. The new labour reform attempts to address all of these factors. This being not because our leaders have come to terms with the new reality, but as the Explanatory Memorandum to the Royal Decree Law 3/2012, states, because it appears that the European and global economic institutions understand better what is occurring to the Spanish labour market. Hence the new government having promised to behave, be obedient and a good sport, and apply the formula proposed by these international institutions, in order to overcome the crisis, the solution to it all: flexisecurity. What is this about? 
Key words: Labour reform of 2012, flexisecurity, measures to promote employability, promotion of long-term contracts, internal and external flexibility.

Sumario: 1. Aproximación al concepto de flexibilidad como fórmula para solucionar los problemas del mercado laboral español.-2. Medidas para favorecer la empleabilidad de los trabajadores. 2.1. Intermediación laboral. 2.2. La formación profesional.-3. Medidas para fomentar la contratación indefinida y para favorecer la creación de empleo. 3.1. El contrato de trabajo por tiempo indefinido de apoyo a los emprendedores. 3.2. Novedades en el contrato a tiempo parcial. 3.3. Trabajo a distancia.-4. Medidas para favorecer la flexibilidad interna en las empresas como alternativa a la destrucción de empleo. 4.1. Sistema de clasificación profesional. 4.2. Tiempo de trabajo. 4.3. Movilidad funcional. 4.4. Movilidad geográfica. 4.5. Modificaciones sustanciales de las condiciones de trabajo. 4.6. Suspensión del contrato de trabajo. 4.7. Negociación colectiva.-5. Medidas para favorecer la eficiencia del mercado de trabajo y reducir la dualidad laboral. 5.1. Suspensión temporal de la aplicación del artículo 15.5 del TRLET. 5.2. Extinción del contrato de trabajo. 5.3. Fondo de garantía salarial.

\section{APROXIMACIÓN AL CONCEPTO DE FLEXIBILIDAD COMO FÓR- MULA PARA SOLUCIONAR LOS PROBLEMAS DEL MERCADO LABORAL ESPAÑOL}

Aunque resulte evidente que las reformas laborales llevadas a cabo por el Gobierno de PSOE durante 2010 y 2011 también buscaron la flexiseguridad requerida por Unión Europea ${ }^{1}$, el Real Decreto-ley 3/2012, de 10 de febrero,

${ }^{1}$ Conforme al Libro Verde de la Comisión Europea «Modernizar el Derecho del Trabajo para afrontar los retos del siglo XXI» [COM (2006) 708 final], la modernización del Derecho del Trabajo se plantea como una estrategia amplia y compleja de reforma de algunos de sus principios básicos, sobre la base de un enfoque integrado de la flexibilidad necesaria para las empresas y la seguridad para los trabajadores. Precisamente, el término «flexiseguridad»se acuñó para referirse a dicho «enfoque integrado». A partir de ese momento, la flexiseguridad se configura como en «nuevo principio ordenador de las políticas laborales y sociales» [MoNeReo PÉrez, J. L. y Fernández AVILÉs, J. A. El debate europeo sobre flexiseguridad en el trabajo (Reflexiones en torno al «Libro Verde» de la Comisión de las Comunidades Europeas). En Lan Harremanak. Revista de Relaciones Laborales, 2007-I, núm. 16, p. 171]. Posteriormente, en la Comunicación de la Comisión al Parlamento Europeo, al Consejo, al Comité Económico y Social Europeo y al Comité de las Regiones «Hacia los principios comunes de flexiseguridad: más y mejor empleo mediante la flexibilidad y la seguridad» [COM (2007) 359 final] se definió el concepto a través de sus cuatro ejes de actuación, a saber: disposiciones contractuales flexibles y fiables; estrategias globales de aprendizaje permanente; políticas activas del mercado laboral eficaces; y Sistemas de Seguridad Social modernos. En líneas generales, puede concluirse que la flexiseguridad adoptada por la Unión Europea pretende combinar la flexibilidad en las condiciones laborales y en el despido con la seguridad en el empleo. Con otras palabras, se pasa de la clásica seguridad del contrato de trabajo a la seguridad del mercado de trabajo y de los mecanismos de Seguridad Social [MoRENo VIDA, M. N. El 


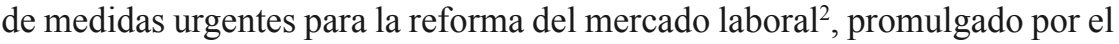
nuevo Gobierno del PP, establece que dichas reformas «aún bienintencionadas $\mathrm{y}$ orientadas en la buena dirección, han sido reformas fallidas» (Exposición de Motivos).

En consecuencia, resulta obligado preguntarse por las novedades que se introducen ahora para implementar adecuadamente la tan ansiada flexiseguridad. Pues bien, tras afirmar que «el objetivo es la flexiseguridad», la Exposición de Motivos del Real Decreto-ley 3/2012 menciona las siguientes cuatro medidas que se pretenden materializar a través de la regulación contenida en su articulado:

(a) Fomentar la empleabilidad de los trabajadores, reformando aspectos relativos a la intermediación laboral y a la formación profesional.

(b) Fomentar la contratación indefinida y otras formas de trabajo con especial hincapié en promover la contratación por PYMES y de jóvenes.

(c) Incentivar la flexibilidad interna en la empresa como medida alternativa a la destrucción del empleo.

(d) Favorecer la eficiencia del mercado de trabajo como elemento vinculado a la reducción de la dualidad laboral, con medidas que afectan principalmente a la extinción de contratos de trabajo.

En principio, de la mera literalidad de estas medidas no se advierte ninguna novedad respecto a las reforma laboral de $2010^{3}$. Por tanto, a continuación, nos centraremos en el análisis del desarrollo de cada una de esas medidas para observar qué hay de nuevo respecto a las medidas ya adoptadas por el anterior Gobierno, y qué hay de cierto en el desiderátum del nuevo Gobierno cuando señala que «la reforma propuesta trata de garantizar tanto la flexibilidad de los empresarios en la gestión de los recursos humanos de la empresa como la seguridad de los trabajadores en le empleo y adecuados niveles de protección social», así como en la afirmación de que «ésta es una reforma en

debate sobre la flexiseguridad en Europa. En Monereo PÉrez, J. L. y SÁnchez Montoya, J. E. (Dirs.), El Derecho del Trabajo y de la Seguridad Social ante la crisis económica, Granada: Comares, 2010, p. 33]. En torno a los problemas de la implantación de la flexiseguridad en España durante el anterior Gobierno del PSOE se refiere OJEDA AVILÉS, bajo la sugerente rúbrica «la flexiseguridad a la española: el Real Decreto-ley 10/2010, de medidas urgentes para la reforma del mercado de trabajo» (OJEDA AVILÉS, A. La deconstrucción del Derecho del Trabajo. Madrid: La Ley, 2010, pp. 590-606). Extensamente sobre la desproporción a favor de la flexibilidad y en contra de la seguridad en las reformas laborales de 2010 y 2011 del Gobierno del PSOE véase FERNÁndEZ FERnÁndEZ, R., ABRIL LARRAÍnZAR, M. P.; y Megino Fernández, D. Dos años de reforma laboral: un análisis teórico-práctico. Madrid: Ediciones CEF, 2011, pp. 37-187.

${ }^{2}$ BOE de 11 de febrero de 2012, núm. 36.

${ }^{3} \mathrm{Se}$ recomienda la toma en consideración de los comentarios que se realizan sobre dicha reforma en ARRIETA IDIAKEZ, F. J. La reforma laboral de 2010. ¿Qué reforma?. En Estudios de Deusto, 2010, vol. 58/2 julio-diciembre. 
la que todos ganan, empresarios y trabajadores, y que pretende satisfacer más y mejor los legítimos intereses de todos» (Exposición de Motivos).

\section{MEDIDAS PARA FAVORECER LA EMPLEABILIDAD DE LOS TRABAJADORES}

\subsection{Intermediación laboral}

La gran novedad consiste en permitir a las Empresas de Trabajo Temporal (ETT) actuar como agencias de colocación ${ }^{4}$. Además, conforme a la nueva redacción de la Disposición Adicional 2 de la Ley 56/2003, de 16 de diciembre de Empleo ${ }^{5}$, cuando actúen como tales lo harán «sin ánimo de lucro», lo que significa «la obligación de garantizar a los trabajadores la gratuidad por la prestación de servicios»».

El Gobierno anterior, en el intento por aumentar la intermediación, permitió que las agencias de colocación tuviesen ánimo de lucro ${ }^{6}$. Igualmente, respecto a las ETT transpuso la Directiva 2008/104/CE, de 19 de noviembre de $2008^{7}$, lo que supuso, además de profundizar en el principio de igualdad de trato en las condiciones laborales entre los trabajadores cedidos y los trabajadores de las empresas usuarias, la supresión de límites y prohibiciones de actuación en los denominados sectores excluidos, es decir, los sectores de riesgo, y dentro de los mismos, con especial importancia, la construcción, y el sector público. Sin embargo, no se posibilitó a las ETT actuar como agencias de colocación, a pesar de que frente al escaso éxito de los servicios públicos de empleo y de las hasta entonces agencias de colocación sin ánimo de lucro, aquéllas fuesen las que más colocaciones realizasen ${ }^{8}$.

Curiosamente, como consecuencia de estas reformas, las ETT encontraron el cauce adecuado para poder colaborar con el sector público, y participar

\footnotetext{
${ }^{4}$ Para ello, además, de obtener la autorización del servicio público de empleo, deberán presentar una declaración responsable mediante la cual se manifieste al servicio público de empleo competente el cumplimiento de los requisitos establecidos en la Ley 56/2003 y su normativa de desarrollo (vid. nueva redacción del artículo 16.3 del Real Decreto Legislativo 1/1995, de 24 de marzo, por el que se aprueba el Texto Refundido de la Ley del Estatuto de los Trabajadores (TRLET).

${ }^{5}$ BOE de 17 de diciembre de 2003, núm. 301.

${ }^{6}$ Artículo 14 de la Ley 35/2010, de 17 de diciembre, de medidas urgentes para la reforma del mercado de trabajo (LMURMT). El desarrollo reglamentario en materia de agencias de colocación se realizó por el Real Decreto 1796/2010, de 30 de diciembre (BOE de 31 de diciembre de 2010, núm. 318). Pese a admitirse las agencias de colocación con ánimo de lucro, se establece la garantía de gratuidad para los trabajadores que acuden a tales agencias.

${ }^{7}$ DOUE de 5 de diciembre de 2008 L 327.

${ }^{8}$ Sobre este hecho, y criticando la oportunidad perdida, véase, PÉrez De Los CoBos OrinuEL, F. La reforma de la intermediación laboral en España. En $A L, 2010$, núm. 5. Versión electrónica: www.laleylaboral.com., pp. 4-5. Y también ARRIETA IDIAKEZ, F.J., ob. cit., pp. 93-94.
} 
en las bases públicas de de ofertas y demandas y recibir financiación en calidad de intermediarios. Simplemente, bastaba con crear una sociedad propia e independiente del negocio de cesión temporal de trabajadores ${ }^{9}$.

En suma, tras la última reforma se ha querido dinamizar el mercado de trabajo reconociendo a las ETT la posibilidad de intervenir como agencias privadas de colocación, confiando en que también a través de esta nueva función consigan los magníficos resultados que vienen obteniendo como empleadores de muchos trabajadores. De hecho, tal y como se reconoce en la Exposición de Motivos del Real Decreto-ley 3/2012, «en la mayoría de los países de la Unión Europea, tales empresas operan como agencias de colocación y desde las instituciones comunitarias se viene subrayando que las mismas contribuyen a la creación de puestos de trabajo y a la participación e inserción en el mercado de trabajo» ${ }^{10}$. Además, este reconocimiento sirve para regularizar una práctica que, como se ha visto, había comenzado a ser realidad, aunque sea valiéndose de operaciones indirectas para separar jurídicamente las funciones de ETT y agencia de colocación.

El tiempo será testigo del éxito de esta apuesta. Ahora bien, en estos tiempos en los que la cuestión de las famosas duplicidades se encuentra tan de moda, cabe preguntarse por el sentido y la eficacia/eficiencia del elevado número de estructuras que desempeñan la función de la intermediación en el mercado de trabajo español. Al disparatado número de servicios públicos de empleo, deben sumarse las cuatro modalidades de agencias de colocación que se permiten en la actualidad ${ }^{11}$. Resulta curioso que un Estado que desea a toda costa centralizar todos los aspectos de la economía y el mercado descentralice y «desparrame» una cuestión tan básica y común como la del empleo.

\footnotetext{
${ }^{9}$ García Romero, B. y Selma Penalva, A. Medidas para favorecer la empleabilidad de los trabajadores. En CAVAS Martínez, F. (Coord.). La reforma laboral de 2012. Análisis del Real Decreto-ley 3/2012... Murcia: Ediciones Laborum, 2012, p. 43. La posibilidad de actuar de este modo se identifica también por AlarCón BRAVO DE RUEDA y MoReno DE VEGA y LOMO, al indicar que «cualquiera de las ETT que han consolidado su presencia en el mercado de trabajo pueden constituir expeditamente una agencia en paralelo, aportando su vasta experiencia con todo tipo de personal» (ALARCón BRAVO DE RUEDA, P. O. y Moreno de Vega y Lomo, F. El nuevo régimen jurídico de las agencias de colocación. En $A L, 2011$, tomo II, núm. 18. Versión electrónica: www.laleylaboral.com., p. 13).

${ }^{10}$ Circunstancia fácilmente constatable en el mercado laboral español, sin que sea necesario que las instituciones comunitarias se lo recuerden al Gobierno.

${ }^{11}$ Agencias de colaboración públicas y privadas, con o sin ánimo de lucro, que realicen labores de intermediación; agencias de colaboración públicas y privadas, con o sin ánimo de lucro, que también desarrollen actuaciones relacionadas con la búsqueda de empleo, tales como orientación e información profesional; agencias de colocación, públicas o privadas, con o sin ánimo de lucro, que lleven a cabo labores de selección de personal; agencias con labores de intermediación destinada a recolocar a los trabajadores (para un análisis den profundidad de todas estas modalidades véase RODRÍGUEZ ESCANCIANO, S. La intermediación en el mercado de trabajo. Análisis y propuestas. Madrid: La Ley, 2012, pp. 305-394.
} 


\subsection{La formación profesional}

Conforme a la Exposición de Motivos del Real Decreto-ley 3/2012, se apuesta «por una formación profesional que favorezca el aprendizaje permanente de los trabajadores y el pleno desarrollo de sus capacidades profesionales» Es más, se llega a afirmar que «el eje básico de la reforma en esta materia es el reconocimiento de la formación profesional como un derecho individual». Pero no es oro todo lo que reluce.

En efecto, en principio, resulta de suma importancia que se reconozca como derecho laboral, en la relación de trabajo, la formación profesional en el trabajo, cuando la misma se dirija a posibilitar la adaptación de los trabajadores a las modificaciones operadas en el puesto de trabajo ${ }^{12}$. En el mismo sentido, en materia de promoción y formación profesional, se regula un nuevo permiso o licencia para los trabajadores con al menos un año de antigüedad en la empresa; este permiso será retribuido y equivaldrá a 20 horas anuales de formación vinculada al puesto de trabajo, pudiendo ser acumulables por un período de hasta 3 años. Además, se crea, aunque quede pendiente de desarrollo reglamentario, la denominada cuenta de formación. Esta cuenta que se asociará al número de afiliación de la Seguridad Social, servirá para que el servicio público de empleo competente recoja la formación recibida por el trabajador a lo largo de su carrera profesional, de acuerdo con el Catálogo de Cualificaciones Profesionales ${ }^{13}$.

Hasta aquí, es evidente que con estos nuevos derechos se refuerza la seguridad de los trabajadores. Sin embargo, las modificaciones operadas en otros preceptos del TRLET pueden dejar en papel mojado dichas mejoras ${ }^{14}$. En concreto, en relación con el ius variandi del empresario en materia de movilidad funcional, la nueva redacción del artículo 39.3 omite la prohibición que antes contenía el mismo; prohibición por la cual dicho ius variandi no podía afectar negativamente a la dignidad de los trabajadores ni a su formación y promoción profesional. Del mismo modo, a partir del 12 de febrero de 2012 (fecha de entrada en vigor del Real Decreto-ley 3/2012) no cabrá la extinción por voluntad del trabajador fundada en causa imputable al empresario, y, por tanto, indemnizable por la cuantía correspondiente al despido improcedente, cuando las modificaciones sustanciales en las condiciones de trabajo

${ }^{12}$ Cfr. nueva redacción del artículo 4.2.b) del TRLET. El mismo derecho vuelve a reiterarse al referirse el TRLET a los derechos que el trabajador tiene en materia de promoción y formación profesional (cfr. nueva redacción del artículo 23.1 del TRLET), con la importante concreción de que el tiempo destinado a la formación se considerará en todo caso tiempo de trabajo efectivo.

${ }^{13}$ Cfr. nueva redacción del artículo 28.10 de la Ley 56/2003, de 16 de diciembre, de Empleo, en relación con la Disposición Final 2 del Real Decreto-ley 3/2012.

${ }^{14} \mathrm{Al}$ respecto véase Molina NAVArReTE, C. De las «Reformas Laborales» a un nuevo, e irreconocible, «Estatuto del Trabajo subordinado». En CEF: Revista de Trabajo y Seguridad Social. Comentarios y caso prácticos, 2012, núm. 348, p. 28. 
redunden en perjuicio de la formación profesional del trabajador como venía reconociéndose hasta la fecha.

En resumen, seguridad sí, reforzándose el derecho individual a la formación, pero supeditada al ius variandi y a las modificaciones sustanciales de las condiciones de trabajo.

Por su parte, más preocupante resulta la regulación del contrato para la formación y el aprendizaje. En realidad, se hereda todo lo negativo de la reforma operada por el anterior Gobierno a través del Real Decreto-ley 10/2011, de 26 de agosto ${ }^{15}$. Pero antes de entrar a analizar este hecho, no cabe olvidar la desastrosa normativa implementada por el anterior Gobierno, y que, por el momento, se mantiene por el actual, en materia de becas ${ }^{16}$. Especialmente agresiva y de una ilegalidad flagrante ${ }^{17}$ resulta el Real Decreto 1543/2011, de 31 de octubre, por el que se regulan las prácticas no laborales en empresas ${ }^{18}$. Pese al intento del legislador de alejar esta nueva modalidad de beca de los contratos de trabajo formativos, para lo que pretende insertarla dentro del denominado «subsistema de formación profesional», un análisis más detallado de las medidas tradicionales de dicho subsistema demuestra claramente la vulneración de la normativa laboral. Podrán alegarse la gravedad de la crisis

${ }^{15}$ BOE de 30 de agosto de 2011, núm. 208.

${ }^{16}$ Tras las reformas materializadas durante el segundo semestre de 2011, nuestros jóvenes cuentan con un régimen de becas de lo más dispar. Para los estudiantes de doctorado debe estarse a lo regulado por el Real Decreto 63/2006, de 27 de enero, por el que se aprueba el Estatuto del Personal Investigador en Formación (BOE de 3 de febrero de 2006, núm. 29). Los jóvenes que durante sus estudios desarrollen actividades formativas bajo el régimen de convenios de cooperación educativa entre sus universidades y empresas o Administraciones públicas (denominados ahora prácticas extracurriculares), así como los que cursen la asignatura de Prácticum (denominada ahora prácticas curriculares) quedan bajo el ámbito de aplicación del Real Decreto 1707/2011, de 18 de noviembre, por el que se regulan las prácticas académicas externas de los estudiantes universitarios (BOE de 10 de diciembre de 2011, núm. 297). Junto a estas dos modalidades de becas, no cabe olvidar las becas reguladas por el Real Decreto 1493/2011, de 24 de octubre (BOE de 27 de octubre de 2011, núm. 259), cuyos destinatarios siguen siendo un auténtico misterio, aunque personalmente me decante por los antiguos becarios de colaboración. Por último, cabe mencionar a los becarios regulados por el Real Decreto 1543/2011, a los que me referiré a continuación.

${ }^{17}$ Sobre esta cuestión resulta de máximo interés el análisis realizado en MARTínEZ GIRÓN, J. Prácticas no laborales en empresas (Análisis crítico del RD 1543/2011, de 31 de octubre). En $A L, 2012$, núm. 6.

${ }^{18}$ BOE de 18 de noviembre de 2011, núm. 278. Nótese que dicha norma se publica en el BOE dos días antes de las elecciones generales. Los destinatarios de estas prácticas no laborales deben ser «personas jóvenes desempleadas inscritas en la oficina de empleo, con edades comprendidas entre 18 y 25 años inclusive, que posean una titulación oficial universitaria, titulación de formación profesional, de grado medio o superior, o titulación del mismo nivel que el de esta última, correspondiente a las enseñanzas de formación profesional, artísticas o deportivas, o bien un certificado de profesionalidad» (Exposición de Motivos). 
económica actual; las altas tasas de desempleo, con especial gravedad entre los jóvenes; la especial dificultad de inserción en el mercado laboral de tales jóvenes etcétera, pero todo ello no puede llevar a ignorar la existencia de los contratos formativos (contrato para la formación y el aprendizaje y contrato en prácticas). Y mucho menos puede ampararse la creación de esta nueva modalidad de beca alegando que las personas jóvenes, aun teniendo una formación académica o profesional acreditada, carecen de experiencia laboral ${ }^{19}$. Porque el objeto de los contratos formativos lo constituye, junto al intercambio de salario por prestación de servicios, la oportunidad concedida por el empresario al trabajador contratado para la obtención, ni más ni menos, de experiencia laboral.

Centrándonos en el contrato para la formación y el aprendizaje, si bien es interesante que se permita recibir la formación en la propia empresa ${ }^{20}$, dado que ello puede permitir una más rápida adaptación del trabajador a los quehaceres de la misma, esta medida no deja de ser un mero espejismo. Ese aparente guiño a la seguridad en el trabajo, queda rápidamente sin valor, pues la regulación, en su conjunto, de esta modalidad contractual es peor que la realizada por el anterior Gobierno. Ciertamente, ambos pecan de desnaturalizar su naturaleza formativa, ya que resulta excesivo que su duración máxima sea de tres años, cuando, recuérdese que la mayoría de estudios de grado se han reducido a cuatro años. Con otras palabras, no es razonable que para la formación universitaria se establezcan 4 años y que para la formación a adquirir mediante el contrato para la formación y el aprendizaje se permita una duración máxima de 3 años. Y es que la desnaturalización formativa de este contrato queda en evidencia cuando ambos Gobiernos toman en consideración «las necesidades organizativas o productivas de las empresas» para alargar su duración.

En íntima conexión con esta desnaturalización, una de las medidas que empeoran la regulación anterior radica en que, durante el segundo y el tercer año de contrato, el tiempo de trabajo efectivo podrá alcanzar el $85 \%$ de la jornada máxima prevista ${ }^{21}$. Esta medida resulta abusiva, pues el tiempo dedicado a la formación es ridículo y, por el contrario, el empresario retribuirá en proporción al trabajo efectivo, es decir, se ahorrará un 15\%, cuando, realmente, los picos de productividad variarán muy poco, dada la naturaleza de las actividades a desarrollar bajo los contratos para la formación y el aprendizaje.

Por otro lado, el poco éxito de esta modalidad contractual para conseguir que un trabajador se inserte en el mercado de trabajo y, tras lograr una buena formación, adquiera el carácter de indefinido (una de los objetivos de la reforma como se verá), se deduce de otra de las desafortunadas modificaciones introducidas en el régimen de este contrato. Efectivamente, ahora se permite que expirada la duración del contrato para la formación y el aprendizaje, el

\footnotetext{
${ }^{19}$ Exposición de Motivos del Real Decreto-ley 1543/2011.

${ }^{20}$ Cfr. nueva redacción del artículo 11.2.d) del TRLET.

${ }^{21}$ Cfr. nueva redacción del artículo 11.2.f) del TRLET.
} 
trabajador pueda ser contratado por la misma o distinta empresa bajo la misma modalidad contractual para desempeñar una distinta actividad laboral u ocupación objeto de cualificación profesional ${ }^{22}$.

Finalmente, no puede pasar por alto, que las empresas que contraten bajo la modalidad de este contrato a desempleados se ahorrarán el 100\% (empresas con plantilla inferior a 250 personas) o el $75 \%$ (empresas con plantilla igual o superior a 250 personas) de las cotizaciones a la Seguridad Social, durante toda la vigencia del contrato ${ }^{23}$. Realmente, no se comprende esta medida, cuando el Sistema público de Seguridad Social requiere de más fondos que nunca, y cuando, no olvidemos, la formación es igual de importante para los trabajadores como para los empresarios.

\section{MEDIDAS PARA FOMENTAR LA CONTRATACIÓN INDEFINIDA Y PARA FAVORECER LA CREACIÓN DE EMPLEO}

\subsection{El contrato de trabajo por tiempo indefinido de apoyo a los emprendedores}

Se trata de una nueva modalidad contractual por tiempo indefinido y a jornada completa que, a pesar de referirse a los «emprendedores», se dirige a la PYMEs (empresas que tengan menos de 50 trabajadores), y que sustituye al hasta ahora vigente contrato para el fomento de la contratación indefinida ${ }^{24}$. Esta sustitución debe ser bien valorada, y esta afirmación debe incluirse en una valoración de mayor alcance. La LMURMT supuso la universalización subjetiva respecto a las personas con las que podía celebrarse el contrato para el fomento de la contratación indefinida. Y ello trajo consigo varias consecuencias.

En primer lugar, se generalizó para todos los despidos objetivos calificados como improcedentes la indemnización reducida de 33 días de salario por año trabajador, con el tope de 24 mensualidades. Esta fue, en realidad, la técnica utilizada por el anterior Gobierno para, sin modificar la cuantía de las indemnizaciones por despido, conseguir un despido más barato. Por tanto, el hecho de que, como se verá más adelante, el nuevo Gobierno haya generalizado en dicha cuantía la indemnización por despido improcedente no resulta una novedad tan importante como la que han transmitido los medios de comunicación.

En segundo lugar, perdió el golpe de efecto necesario para que los empresarios contratasen a los segmentos poblacionales que más sufren las crisis.

${ }^{22}$ Cfr. nueva redacción del artículo 11.2.c) del TRLET.

${ }^{23}$ Cfr. artículo 3 del Real Decreto-ley 3/2012.

${ }^{24}$ Téngase en cuenta que la Disposición Derogatoria única del Real Decreto-ley 3/2012 deroga la Disposición Adicional 1 de la Ley 12/2001, de 9 de julio, de medidas urgentes de reforma del mercado de trabajo para el incremento del empleo y la mejora de su calidad (BOE de 10 de julio de 2001, núm. 164). 
Por consiguiente, la nueva modalidad contractual creada puede considerarse, grosso modo, como un retorno al contrato de fomento de la contratación indefinida originario. Ahora bien, los incentivos establecidos para que los empresarios opten por su utilización comportan importantes novedades. Así, además de importantes incentivos fiscales y bonificaciones, siempre y cuando se contrate a jóvenes menores de 30 años y determinados desempleados ${ }^{25}$, se establece un período de prueba de un año en todo caso. Sin duda, este último aspecto se convertirá en el principal incentivo de este contrato para todos aquellos empresarios que utilicen el período de prueba de manera fraudulenta, olvidando la verdadera finalidad del mismo. De esa manera, no solamente quedará desfigurada la naturaleza de esta nueva modalidad contractual, pues, en realidad, quedará transformada, por el mal uso del período de prueba, en un contrato temporal, sino que el despido será sin causa y gratuito. Precisamente por ello, debe concluirse que este precepto alberga «alguna dosis de inconstitucionalidad de baja intensidad (artículos 35 y $38 \mathrm{CE}$ ) que quizá debiera conducir a una reconsideración a la baja de su duración en el trámite parlamentario $»^{26}$. A mayor abundamiento, debe recordarse que el Convenio núm. 158 de la OIT, de 22 de junio de 1982, sobre la terminación de la relación de trabajo por iniciativa del empleador (ratificado por España el 26 de abril de 1985), permite excluir de su protección a los trabajadores que estén en período de prueba, siempre que su duración «se haya fijado de antemano y sea razonable» (artículo 2.2.b). En ese sentido, la duración de un año, en todo caso, del período de prueba, «generalizada para toda actividad, trabajador, empresa y sector desnaturaliza dicho período, convirtiendo la previsión en irrazonable $»^{27}$. Por su parte, la jurisprudencia también ha aplicado la doctrina del abuso de derecho respecto a las cláusulas convencionales sobre el período de prueba, cuando las mismas establecen plazos de larga duración que exceden de la finalidad atribuida al período de prueba ${ }^{28}$.

${ }^{25}$ Respecto a tales incentivos fiscales y bonificaciones véase el artículo 4, apartados 5 a 9, del Real Decreto-ley 3/2012.

${ }^{26}$ Sempere Navarro, A. V. y Matín Jiménez, R. Claves de la reforma laboral de 2012 (Estudio del RDley 3/2012, de 10 de febrero). Cizur Menor: Aranzadi, 2012, p. 183.

${ }^{27}$ Luján Alcaraz, J. y Ríos Mestre, J. M. Contrato indefinido de apoyo a los emprendedores; supresión del contrato para el fomento de la contratación indefinida. En CAVAS Martínez, F. (Coord.). La reforma laboral de 2012. Análisis del Real Decreto-ley 3/2012... Murcia: Ediciones Laborum, 2012, pp. 88-89.

${ }^{28}$ Por todas, STS, ud., de 12 de noviembre de 2007 (rec. 4341/2006), que considera abusiva por contrariar la finalidad del período de prueba una cláusula convencional en la que se establece un período de prueba de 2 años para determinado personal de ventas. En último término se concluye que «no parece razonable admitir que el empresario necesite de un periodo de prueba tan largo para advertir la capacitación profesional en una actividad de estas características» ( $2^{\circ}$ FD). Más recientemente, la STS, ud., de 20 de julio de 2001 (rec. 152/2010), recuerda, en primer lugar, que «la finalidad del instituto del período de 


\subsection{Novedades en el contrato a tiempo parcial}

La gran novedad consiste en que a los trabajadores a tiempo parcial se les reconoce la posibilidad de realizar horas extraordinarias ${ }^{29}$. Con ello se pretende aumentar el número de contratos celebrados bajo esta modalidad, dado su escaso éxito en España. Este interés se debe a que el Gobierno considera que «el trabajo a tiempo parcial no sólo es un mecanismo relevante en la organización flexible del trabajo y en la adaptación del tiempo de trabajo a las necesidades profesionales y personales de los trabajadores, sino que es un mecanismo de redistribución del empleo» (Exposición de Motivos del Real Decreto-ley 3/2012).

Sin duda, la posibilidad de realizar horas extraordinarias introduce un importante grado de flexibilidad en el contrato, de forma y manera que el empresario podrá valerse de las personas contratadas a tiempo parcial, sin necesidad de contratar a terceras personas para cubrir las eventuales necesidades requeridas por el proceso productivo. En verdad, podría haberse modificado el régimen existente en torno a las horas complementarias para conseguir el mismo fin, pero no ha sido así. Por consiguiente, un mimo trabajador que, conforme a la definición del artículo 12.1 del TRLE, preste sus servicios a tiempo parcial, podrá realizar, al mismo tiempo, horas complementarias y horas extraordinarias. Es cierto que se hace hincapié en que «el número de horas extraordinarias que se podrán realizar será el legalmente previsto en proporción a la jornada pactada» o en que «en todo caso, la suma de las horas ordinarias, extraordinarias y complementarias no podrá exceder del límite legal del trabajo a tiempo parcial», pero el cumplimiento de todo ello no siempre será fácil y dependerá del grado de control que desempeñen los representantes de los trabajadores y la Inspección de Trabajo.

prueba es la experimentación "sobre el terreno" de la relación de trabajo mediante la ejecución de las prestaciones respectivas de las partes, siendo sus funciones manifiestas la comprobación de la aptitud profesional y la adaptación al puesto de trabajo del trabajador contratado, teniendo mayor significación estas funciones en los trabajos cualificados y de dirección o supervisión, que en otros menos cualificados y tiene, consustancialmente, un carácter de temporalidad y provisionalidad, y de ahí, que sea razonable, que su duración sea por lo general, breve» ( $\left.2^{\circ} \mathrm{FD}\right)$. Y, en coherencia con tal afirmación, declara inaplicable por abusivo el período de prueba de 1 año establecido en una cláusula convencional para un trabajador no cualificado (personal de grupo de ventas), razonando que «debe sostenerse, que la negociación colectiva no puede magnificarse hasta el extremo de admitir como válidas fórmulas convencionales que pueden resultar incompatibles con la propia finalidad y funciones del instituto del período de prueba, pues una regulación convencional en la que se fije una duración excesivamente dilatada de dicho período, bien puede sugerir que se esté dando amparo a un resultado que, en la práctica, puede asemejarse a la funcionalidad real de los contratos temporales, lo que podría encubrir situaciones de fraude de ley al poder utilizarse para enmascarar unos fines no queridos por el citado precepto estatutario. Dichas cláusulas son radicalmente nulas por contrarias a la ley y al orden público social» $\left(2^{\circ} \mathrm{FD}\right)$.

${ }^{29}$ Cfr. nuevo artículo 12.4.c) del TRLET. 
Por otro lado, el Gobierno pretende compensar la flexibilidad referida con la seguridad en materia de protección social; para ello, se establece que «las horas extraordinarias realizadas en el contrato a tiempo parcial computarán a efectos de bases de cotización a la Seguridad Social y bases reguladoras de las prestaciones». Debe recordarse que hasta ahora, y excluidos los trabajadores contratados a tiempo parcial, el importe de las horas extraordinarias se tenía en cuenta solamente para la determinación de las bases de cotización por contingencias profesionales $^{30}$.

\subsection{Trabajo a distancia}

Sin duda, la regulación del trabajo a distancia en el artículo 13 del TRLET, sustituyendo de esa manera a la antigua regulación del contrato de trabajo a domicilio, persigue contemplar el teletrabajo desde el punto de vista del Derecho laboral, aunque sin dejar de dar cabida a otras formas de trabajo a distancia, entre las que se incluye el trabajo a domicilio que se desarrolle sin tecnologías de la información y la comunicación ${ }^{31}$. Así se deduce de la propia Exposición de Motivos del Real Decreto-ley 3/2012, cuando ésta señala que «el deseo de promover nuevas formas de desarrollar la actividad laboral hace que dentro de esta reforma se busque también dar cabida, con garantías, al teletrabajo». Además, acto seguido, se ofrece una acertadísima definición de teletrabajo: «una particular forma de organización del trabajo que encaja perfectamente en el modelo productivo y económico que se persigue, al favorecer la flexibilidad de las empresas en la organización del trabajo, incrementar las oportunidades de empleo y optimizar la relación entre tiempo de trabajo y vida personal y familiar».

No obstante, nótese que ahora se regula «una particular forma de organización del trabajo» y no una nueva modalidad contractual. Con otras palabras, los trabajadores a distancia podrán celebrar cualquiera de las modalidades de contrato de trabajo aceptadas por el ordenamiento jurídico laboral, siempre y cuando exista la causa del contrato en cuestión y se den las notas de laboralidad. En consecuencia, ahora se regulan unas condiciones que todo contrato de trabajo deberá respectar cuando la prestación de servicios se materialice a distancia. De este modo, en lo que respecta al teletrabajo, se pone fin a la necesidad de diferenciar entre sus modalidades on-line y off-line, pues ya no se exige, como ocurría en el antiguo contrato de trabajo a domicilio, que el trabajo se realice «sin vigilancia del empresario».

${ }^{30}$ A concretar los cambios operados para dotar de mayor seguridad a los trabajadores a tiempo parcial que realicen horas extraordinarias se dedica la Disposición Final 9 del Real Decreto-ley 3/2012.

${ }^{31}$ En este sentido, Muñoz Ruiz, A. B. Trabajo a distancia. En García-Perrote EsCartín, I. y Mercader Uguina, J. R., (Dirs.). Reforma laboral 2012. Análisis práctico del $R D L$ 3/2012... Valladolid: Lex Nova, 2012, pp. 116-117. 
En concreto, las condiciones que deberán respetarse cuando el trabajo se realice a distancia son las siguientes: (a) la prestación de servicios deberá llevarse a cabo de manera preponderante en el domicilio del trabajador o en el lugar libremente elegido por éste, de modo alternativo a su desarrollo presencial en el centro de trabajo de la empresa; (b) la posibilidad de trabajar a distancia será siempre el resultado del acuerdo entre el empresario y el trabajador, debiéndose recoger dicho acuerdo por escrito; (c) los trabajadores a distancia tendrán los mismos derechos que los que prestan sus servicios en el centro de trabajo de la empresa, salvo aquéllos que sean inherentes a la realización de la prestación laboral en el mismo de manera presencial; en especial, se reconoce al trabajador a distancia el derecho a percibir, como mínimo, la retribución total establecida conforme a su grupo profesional y funciones, así como el acceso efectivo a la formación profesional continua; (d) los trabajadores a distancia tienen asegurados sus derechos colectivos, ya que deben estar adscritos a un centro de trabajo concreto de la empresa ${ }^{32}$.

Por el contrario, se echa de menos la regulación de un documento similar al «documento de control de la actividad laboral», que se contemplaba en la antigua redacción del artículo 13.4. La importancia de este documento radicaba en que a través de su contenido quedaban aclaradas algunas cuestiones que a día de hoy se silencian, entre las que destacan la cantidad de materias primas entregadas y la regulación relativa a los gastos ocasionados al trabajador por el mero hecho de trabajar a distancia (adecuación del lugar de trabajo, ADSL, impresora, calefacción, teléfono, electricidad, etc. $)^{33}$.

\section{MEDIDAS PARA FAVORECER LA FLEXIBILIDAD INTERNA EN LAS EMPRESAS COMO ALTERNATIVA A LA DESTRUCCIÓN DE EMPLEO}

\subsection{Sistema de clasificación profesional}

Una de las grandes novedades de la reforma laboral implementada por el Real Decreto-ley 3/2012 consiste en la eliminación de las categorías pro-

${ }^{32}$ La efectividad de estas medidas pasa por la implicación de los representantes de los trabajadores y el interés del propio trabajador a distancia, pues a través del correo electrónico podrá intercambiarse la información relacionada con la defensa de los intereses de los trabajadores. De hecho, esa forma de actuar se está convirtiendo en el principal cauce de comunicación incluso para con los trabajadores que prestan sus servicios de manera presencial en el centro de trabajo. Es más, como recuerda la STC 289/2005, de 7 de noviembre, la empresa debe facilitar a los representantes de los trabajadores los medios informáticos, siempre y cuando tales medios se utilicen para difundir información sindical o de naturaleza laboral y no se perjudique el normal desarrollo de la actividad empresarial.

${ }^{33}$ CAMPs RuIZ, L. M. Contratación, formación y empleo en el RDL 3/2012. En VVAA. La reforma laboral en el Real Decreto-ley 3/2012. Valencia: Tirant lo Blanch, p. 78. 
fesionales como sistema de clasificación profesional. De este modo, el sistema de clasificación profesional pasa a tener como única referencia el grupos profesional «con el objetivo de sortear la rigidez de la noción de categoría profesional y hacer de la movilidad funcional ordinaria un mecanismo de adaptación más viable y eficaz» (Exposición de Motivos).

A primera vista, esta medida puede resultar interesante por el simple hecho de simplificar la forma de entender el sistema de clasificación profesional, que con anterioridad a la reforma en muchas ocasiones resultaba ciertamente farragoso, pues era frecuente mezclar los conceptos de grupo profesional, categoría profesional y puesto de trabajo. Así, desde este prisma, se evitarán con mayor facilidad los fraudes en la concatenación de contratos temporales ${ }^{34}$. Pero puede producirse mayor precariedad, pues ahora se dispone que «cuando se acuerde la polivalencia funcional o la realización de funciones propias de más de un grupo, la equiparación se realizará en virtud de las funciones que se desempeñen durante mayor tiempo ${ }^{35}$. En efecto, la posible precariedad aludida trae causa de la falta de concreción de la referencia «durante mayor tiempo» y del hecho de que ahora la equiparación se realiza teniendo ese criterio y no las funciones prevalentes, de entre todas las que se desarrollen, como sucedía con anterioridad.

Por otro lado, no cabe olvidar que el éxito de la apuesta por los grupos profesionales como sistema de clasificación depende del grado de formación que tengan los trabajadores.

\subsection{Tiempo de trabajo}

Tras la reforma se permite que, en defecto de pacto, la empresa pueda distribuir de manera irregular a lo largo del año el 5 por ciento de la jornada de trabajo ${ }^{36}$.

\footnotetext{
${ }^{34}$ Recuérdese que el artículo 15.5 tiene en cuenta para evitar la concatenación de contratos temporales, entre otras circunstancias, el hecho de que se contrate a una misma persona «para el mismo o diferente puesto de trabajo con la misma empresa o grupo de empresas». La indefinición que existe en el TRLET respecto al concepto de «puesto de trabajo», unido a la existencia, antes de la reforma laboral actual, de distintas «categorías profesionales», creaba problemas de interpretación que ahora quedan subsanados, pues el «grupo profesional», constituido como único sistema de clasificación, agrupa ahora «unitariamente las aptitudes profesionales, titulaciones y contenido general de la prestación, y podrá incluir distintas tareas, funciones, especialidades profesionales o responsabilidades asignadas al trabajador». Por todo ello, considero que tras los últimos cambios, la prohibición de concatenación afecta ahora a la sucesiva contratación para prestar servicios dentro de un mismo grupo profesional, es decir, solamente podrá celebrarse un segundo contrato temporal, sin que se produzcan las consecuencias de la prohibición de la concatenación, cuando dicho contrato se celebre para desarrollar funciones de otro grupo profesional.

${ }^{35} \mathrm{Cfr}$. nueva redacción del artículo 22.4 , in fine, del TRLET.

${ }^{36} \mathrm{Cfr}$. nueva redacción del artículo 34.2 del TRLET.
} 


\subsection{Movilidad funcional}

Se flexibiliza la posibilidad de que el empresario asigne a los trabajadores funciones inferiores, no correspondientes a su grupo profesional, pues tras la reforma tal posibilidad ya no se vincula a «necesidades perentorias o imprevisibles de la actividad productiva».

\subsection{Movilidad geográfica}

La flexibilización en esta materia se ha materializado vinculando las razones económicas, técnicas, organizativas o de producción, que deben justificarse en todo caso, a la «competitividad, productividad u organización técnica o del trabajo en la empresa, así como [a] las contrataciones referidas a la actividad empresarial $»^{37}$. Dicho con otras palabras, basta con que el empresario alegue cualquier aspecto relacionado con estas últimas circunstancias para que pueda proceder a realizar la movilidad geográfica, siempre y cuando se atenga a los requisitos procedimentales establecidos en el propio artículo 40 del TRLET. Con ello se pierde la configuración teleológica requerida con anterioridad a la reforma, en la medida en que antes era necesario que el empresario vinculase las razones económicas, técnicas, organizativas o de producción a la adopción de una serie de medidas que contribuyesen a «mejorar la situación de la empresa a través de una adecuada organización de sus recursos que favorezca su posición competitiva en el mercado o una mejor respuesta a las existencias de la demanda ${ }^{38}$. Si de por sí ya resultaba difícil apreciar en sede judicial una relación causal entre las razones alegadas por el empresario y las medidas adoptadas por éste con fines a futuro - por lo que, en último término, la valoración de las medidas adoptadas quedaba siempre al mejor criterio del órgano judicial-, tras barajar las distintas posibilidades para solventar los problemas planteados por el empresario, ahora ni siquiera cabe tal posibilidad.

Con el mismo objetivo de flexibilización, y, en este caso, también de agilizar el procedimiento de traslado colectivo, se ha eliminado la posibilidad de que la autoridad laboral, tras la finalización del período de consultas, a la vista de las posiciones de las partes y siempre que las consecuencias económicas y sociales de la medida así lo justifiquen, pueda ordenar la ampliación del plazo de incorporación de los trabajadores a sus nuevos destinos y la consiguiente paralización de la efectividad del traslado por un período de tiempo, que en ningún caso, sea superior a 6 meses $^{39}$.

Por último, como consecuencia de la reforma, se introduce en el artículo 40.5 una posibilidad que aunque no se hubiese establecido podría haberse lle-

\footnotetext{
${ }^{37}$ Cfr. nueva redacción del artículo 40.1 del TRLET.

${ }^{38} \mathrm{Cfr}$. anterior redacción del artículo 40.1 del TRLET.

${ }^{39} \mathrm{Cfr}$ anterior redacción del artículo 40.2 del TRLET.
} 
vado a cabo igualmente. En concreto, el precepto mencionado señala ahora, a efectos de permanencia en el puesto de trabajo y evitar el traslado, que «mediante convenio colectivo o acuerdo alcanzado durante el período de consultas se podrán establecer prioridades de permanencia a favor de trabajadores de otros colectivos [al margen de la clásica prioridad de los representantes legales de los trabajadores], tales como trabajadores con cargas familiares, mayores de determinada edad o personas con discapacidad».

\subsection{Modificaciones sustanciales de las condiciones de trabajo}

Se ha realizado una modificación idéntica a la realizada en materia de movilidad geográfica, es decir, se ha flexibilizado demasiado el sentido de las razones económicas, técnicas, organizativas o de producción, relacionándolas con «la competitividad, productividad u organización técnica o del trabajo en la empresa ${ }^{40}$. Con ello, al igual que sucede en la movilidad geográfica, el juez pierde toda facultad de valoración, pues desaparece cualquier atisbo teleológico de las medidas adoptadas por el empresario. Cualquier circunstancia que alegue el empresario relacionada con la competitividad, la productividad o la organización técnica o del trabajo en la empresa es suficiente para que se materialice la modificación sustancial en las condiciones de trabajo. Ya no es necesario que las medidas que adopte contribuyan a «prevenir una evolución negativa de la empresa o a mejorar la situación y perspectivas de la misma a través de una más adecuada organización de sus recursos, que favorezca su posición competitiva en el mercado o una mejor respuesta a las exigencias de la demanda» ${ }^{41}$. En resumen, el empresario se convierte en el «amo y señor» de la valoración de las razones que pueden dar lugar a tales modificaciones.

En particular, en lo que se refiere a las materias que pueden ser objeto de modificación sustancial, ahora se menciona expresamente junto al «sistema de remuneración», la «cuantía salarial», lo que, en realidad, no deja de ser tan trascendental, pues es sabido que la enumeración de materias que realiza el artículo 41.1 del TRLET es numerus apertus.

En otro orden de cosas, «se simplifica la distinción entre modificaciones sustanciales individuales y colectivas» (Exposición de Motivos). En efecto, conforme a los cambios introducidos por el Real Decreto-ley 3/2012, la modificación sustancial de las condiciones de trabajo se considerará colectiva atendiendo solamente al número de trabajadores de la plantilla afectados, a saber, «se considerará de carácter colectivo la modificación que, en un período de 90 días, afecte al menos a: (a) 10 trabajadores, en las empresas que ocupen menos de 100 trabajadores; (b) el 10\% del número de trabajadores de la empresa en aquellas que ocupen entre 100 y 300 trabajadores; (c) 30 trabajadores, en las empresas que ocupen más de 300 trabajadores» (artículo 41.2 del

${ }^{40}$ Cfr. nueva redacción del artículo 41.1 del TRLET.
${ }^{41} \mathrm{Cfr}$. antigua redacción del artículo 41.1 del TRLET. 
TRLET). Ello significa que se flexibiliza, a efectos procedimentales, la modificación de condiciones fijadas en pacto colectivo, pues las mismas se considerarán individuales si no afectan al número de trabajadores mencionado. Por su parte, la modificación de las condiciones de trabajo reguladas en convenios colectivos estatutarios pasa ahora a contemplarse en el ámbito de los descuelgues del convenio colectivo ${ }^{42}$. Precisamente, en relación con el procedimiento, también se reduce de 30 a 15 días la antelación con la que el empresario debe notificar a los trabajadores su intención de llevar a cabo una modificación individual ${ }^{43}$. Además, se incluye la modificación sustancial de funciones y de estructura y cuantía salarial como causa de extinción voluntaria del contrato de trabajo con derecho a indemnización ${ }^{44}$. Por último, la decisión sobre la modificación colectiva de las condiciones de trabajo que debe ser notificada por el empresario a los trabajadores una vez finalizado el período de consultas sin acuerdo surtirá efectos en el breve plazo de los 7 días siguientes a su notificación, y no en los 30 días que se establecían antes ${ }^{45}$.

\subsection{Suspensión del contrato de trabajo}

Con la nueva reforma se agiliza el procedimiento para que el empresario pueda suspender contratos de trabajo, ya que se suprime el requisito de autorización administrativa (ERE suspensivo) y las funciones de la autoridad laboral se limitan a dar traslado de la comunicación del empresario a la entidad gestora de las prestaciones por desempleo y a recabar informe preceptivo de la Inspección de Trabajo sobre los extremos de dicha comunicación y sobre el desarrollo del período de consultas, así como a informar a la entidad gestora de la prestación por desempleo la decisión del empresario tras el período de consultas. La autoridad laboral solamente podrá impugnar el acuerdo logrado entre el empresario y los representantes de los trabajadores, a petición de la entidad gestora de la prestación por desempleo, cuando el acuerdo pueda tener por objeto la obtención indebida de las prestaciones por parte de los trabajadores afectados por inexistencia de la causa motivadora de la situación legal de desempleo. En resumen, a partir de ahora la autoridad laboral se limitará a velar por el buen funcionamiento de los trámites que el empresario debe desarrollar de cara a suspender los contratos de trabajo.

Además, ahora no se define, ni siquiera por remisión a los artículos 40, 41 o 51, lo que debe entenderse por causas económicas, técnicas, organizativas o de producción, lo que aumenta la incertidumbre.

${ }^{42}$ Por ende, se produce una remisión al artículo 82.3 del TRLET en la nueva redacción que presenta el artículo 41.6 del TRLET.

${ }^{43}$ Cfr. nueva redacción del artículo 41.3 del TRLET.

${ }^{44}$ Ibidem.

${ }^{45}$ Cfr. nueva redacción del artículo 41.5 del TRLET. 
Finalmente, después de tanta flexibilidad, se hace un guiño a la seguridad de los trabajadores, al reconocerles el derecho a la reposición de la duración de la prestación por desempleo en los términos establecidos en el artículo 16 del Real Decreto-ley 3/2012. Por el contrario, lo que nuevamente no se entiende es que se regulen medidas de apoyo a los empresarios, principalmente, vía bonificaciones en las cuotas empresariales a la Seguridad Social, para que procedan a la suspensión de contratos y a la reducción de jornada ${ }^{46}$.

\subsection{Negociación colectiva}

No es ninguna novedad que se intente la flexibilidad interna modificando aspectos de la regulación relativa a la negociación colectiva, pues el Gobierno anterior ya procedió a introducir cambios a través del Real Decreto-ley 7/2011, de 10 de junio, de medidas urgentes para la reforma de la negociación colectiva ${ }^{4}$. Por ello, el nuevo Gobierno asume la realidad precedente y se limita a avanzar en algunos aspectos, cumpliendo así su objetivo de introducir mayor flexibilidad, o, simplemente, a «retocar» algunos aspectos. Vayamos por partes.

(a) Eficacia del convenio colectivo (artículo 82.3 del TRLET): se generaliza la posibilidad del descuelgue del convenio colectivo aplicable en la empresa, en muchas y muy importantes materias (jornada de trabajo, horario y distribución del tiempo de trabajo; régimen de trabajo a turnos; sistema de remuneración y cuantía salarial; sistema de trabajo y rendimiento; funciones, cuando excedan de los límites que para la movilidad funcional prevé el artículo 39 del TRLET). Para que el empresario pueda llevar a cabo tales descuelgues es preciso que concurran causas económicas, técnicas, organizativas o de producción. En este caso sí se procede a describir cada una de esas causas, y para ello se vuelve a reiterar lo regulado a efectos de los despidos colectivos (infra 5.2). Procedimentalmente, el empresario tiene la obligación de desarrollar un período de consultas con los representantes de los trabajadores. Así cuando llegue a un acuerdo con los mismos, éste deberá determinar con exactitud las nuevas condiciones de trabajo aplicables a la empresa y su duración. Hasta aquí todo parece correcto, dado que las empresas deben ser cada vez más dinámicas y flexibles para poder adaptarse con rapidez no ya solamente a los períodos de crisis como los que vivimos, sino que también a las exigencias del mercado globalizado. No obstante, el empresario puede acabar materializando el descuelgue del convenio a pesar de no conseguir un acuerdo con los representantes de los trabajadores, al igual que ocurría tras la reforma del anterior Gobierno respecto a cualquier materia regulada en un convenio colectivo estatutario (aunque con algunos límites respecto a los convenios sectoriales), por la vía de la modificación sustancial de las condiciones de trabajo del artículo 41 del TRLET. Ciertamente, ello se debe a que las discrepancias entre el empresario y el trabajador siempre podrán trasladarse a la Comisión Consultiva Nacional de

\footnotetext{
${ }^{46}$ Cfr. artículo 15 del Real Decreto-ley 3/2012.

${ }^{47}$ BOE de 11 de junio de 2011, núm. 139.
} 
Convenios Colectivos, cuando la inaplicación de las condiciones de trabajo afecte a centros de trabajo de la empresa situados en el territorio de más de una comunidad autónoma, o a los órganos correspondientes de las comunidades autónomas en los demás casos. Además, estos mismos órganos podrán designar un árbitro al efecto. Al respecto, debe matizarse que nos encontramos ante una solución de dudosa constitucionalidad, pues el laudo impuesto en tales supuestos afecta a la libertad sindical y al derecho a la negociación colectiva ${ }^{48}$.

(b) Concurrencia de convenios (articulo 84.1 del TRLET): se mantiene la no afección del convenio colectivo durante su vigencia, con la excepción de lo que pueda decidirse en los acuerdos interprofesionales. Igualmente, se mantiene la primacía otorgada por la anterior reforma al convenio de empresa. Simplemente se reordena la exposición respecto a la reforma anterior y ahora se impide que se disponga en los acuerdos interprofesionales sobre la prioridad aplicativa del convenio de empresa. En líneas generales, se considera adecuada la prevalencia de los convenios de empresa, por las mismas razones expuestas en el apartado anterior, independientemente de que ello suponga un reto para los sindicatos, dado que las pequeñas empresas se encuentran escasamente sindicalizadas. Obviamente, los sindicatos se sienten más cómodos en los ámbitos en los que rige el criterio de la máxima o cuasi máxima representatividad, pero los tiempos han cambiado y, con ello, también las necesidades de las empresas.

(c) Contenido mínimo del convenio colectivo (artículo 85.3 del TRLET): se simplifica bastante respecto a la reforma anterior, sobre todo, en materia de funciones asignadas a la comisión paritaria. A pesar de ello, dicha simplificación debe valorarse positivamente, pues la redacción anterior resultaba excesivamente complicada.

(d) Vigencia (artículo 86. apartados 1 y 3 del TRLET): como novedad se posibilita expresamente que, durante la vigencia del convenio colectivo, los sujetos que reúnan los requisitos de legitimación necesarios negocien su revisión. Asimismo, se establece un plazo máximo de 2 años para negociar un nuevo convenio colectivo una vez que se produzca la denuncia del anterior. Ahora bien, si transcurridos esos 2 años no se acuerda un nuevo convenio, salvo pacto en contrario, se aplicará automáticamente el convenio colectivo de ámbito superior. En relación con el pacto en contrario, a día de hoy, parece poco probable que se produzca, dado que lo normal es que el empresario quiera «suavizar» las condiciones de un convenio anterior elaborado en un período anterior a la crisis. Respecto a las posibilidades de aplicación del convenio superior o de la inexistencia del mismo, se abren las puertas a las modificaciones sustanciales de las condiciones de trabajo (en el primero de los casos, obviamente, cuando los contratos de los trabajadores contengan mejores condiciones, en virtud de las incorporaciones realizadas vigente el anterior convenio).

${ }^{48}$ Sempere Navarro, A. V. y Martín Jiménez, R., ob. cit., p. 64. 
(e) Tramitación del nuevo convenio colectivo (artículo 89.2 del TRLET): se elimina la excesiva intromisión del legislador que se manifestaba en la redacción de la reforma anterior, y ahora sólo se regula la obligación de constituir la comisión negociadora del nuevo convenio en el plazo de 1 mes.

\section{MEDIDAS PARA FAVORECER LA EFICIENCIA DEL MERCADO DE TRABAJO Y REDUCIR LA DUALIDAD LABORAL}

\subsection{Suspensión temporal de la aplicación del artículo 15.5 del TRLET}

El nuevo Gobierno ha decidido detener la suspensión que el anterior Gobierno había decidido respecto a la norma antiencadenamiento o anticoncatenación de contratos temporales contenida en el artículo 15.5 del TRLET. Se trata de una decisión totalmente lógica, coherente. Es más, razones de seguridad jurídica - debido a las expectativas creadas a los empresarios por la suspesión - justifican que no se haya eliminado la suspensión desde la entrada en vigor del Real Decreto-ley 3/2012, sino que, por el contrario, se haya establecido una vacatio legis de un año, es decir, la suspensión del artículo 15.5 seguirá vigente hasta el 31 de diciembre de 2012, cuando el Gobierno anterior había previsto su vigencia hasta el 31 de agosto de 2013.

Sin lugar a dudas, merece detenerse en la evolución de esta figura, para percatarse de la forma de legislar en España. El Gobierno socialista anunció a bombo y platillo la medida anticoncatenación introducida en el artículo 15.5 del TRLET en la reforma laboral de 2006. Sin embargo, un análisis pausado de la misma evidenciaba importantes fisuras por las que podía dejarse sin aplicación ${ }^{49}$. Posteriormente, en la reforma de 2010, el mismo Gobierno introdujo algunos ajustes en la regla instaurada en $2006^{50}$, y, finalmente, a través del Real Decreto-ley 10/2011, de 26 de agosto, procedió a implementar su suspensión, a escasos cuatro meses de las elecciones generales. Curiosamente, de la lectura de la Exposición de Motivos de esta última norma se deduce el intento a la desesperada de un Gobierno agonizante por descender las elevadísimas tasas de desempleo generadas durante su mandato. Se vuelve a repetir la historia con el mismo Gobierno, pues nuevamente, como sucedió a raíz de la Ley 32/1984, de 2 de agosto ${ }^{51}$, se intenta

${ }^{49} \mathrm{Al}$ respecto véase ARrietA IDIAKEZ, F. J. La reforma de 2006 sobre el mercado de trabajo. Principales repercusiones en la contratación temporal. En $A L, 2007$, núm. 15, pp. 1797-1806.

${ }^{50}$ Sobre estos ajustes véase ARRIETA IdiAKEZ, F. J. La reforma laboral de 2010. ¿Qué reforma?. En Estudios de Deusto, 2010, vol. 58/2 julio-diciembre, p. 79-81.

${ }^{51}$ BOE de 4 de agosto de 1984, núm. 186. Sin duda, esta reforma pasó a la historia por descausalizar la contratación temporal, pues, mientras subsistiesen la crisis económica y las altas tasas de desempleo, se consideró oportuno permitir la celebración de contratos de duración determinada como medida de fomento del empleo. Esta última circunstancia generó en el empresariado español la cultura de la temporalidad, que ha perdurado hasta nuestros días, en perjuicio de la contratación indefinida, pese a que ésta siga siendo la modalidad contractual arquetípica del TRLET. 
justificar que más vale un contrato temporal en precario y, por cierto, en fraude de ley, que formar parte de las listas del paro. Ciertamente, esta medida no encaja con la tendencia a incrementar la contratación indefinida que defienden tanto el Gobierno actual como el anterior, e incluso va en contra de la ansiada flexiseguridad, pues con la misma nos quedamos en «flexiprecariedad». De ahí lo razonable de su eliminación.

\subsection{Extinción del contrato de trabajo}

Las medidas adoptadas en este campo han sido consideradas por los medios de comunicación como las más agresivas de la reforma. Sin embargo, tales medidas merecen un análisis más pausado.

(a) Despido colectivo (artículo 51 del TRLET): se eliminan las parcas referencias que posibilitaban entender equilibrada la decisión extintiva respecto a la situación negativa de la empresa («viabilidad de la empresa», «capacidad de mantener el volumen de empleo», «preservar o favorecer su posición competitiva en el mercado»). Pero a grandes rasgos se mantienen las tremendamente flexibles definiciones de las causas económicas, técnicas, organizativas o de producción en las que debe fundarse la extinción del contrato de trabajo, y que fueron establecidas por el Gobierno anterior ${ }^{52}$. En ese sentido, se introducen dos modificaciones que aumentan más, si cabe, dicha flexibilidad de salida del mercado de trabajo. La primera de ellas se centra en las causas económicas, pues a partir de la reforma, junto a la disminución del nivel de ingresos, se entiende por tal también la disminución de ventas. Además, se matiza que «en todo caso, se entenderá que la disminución es persistente si se produce durante 3 trimestres consecutivos». Pero de nuevo cabe preguntarse por la cuantía de dicha disminución, más que por la duración de la misma. ¿Dichas disminuciones son suficientes como para hacer dejación del principio de conservación del negocio jurídico? ¿Es así como se pretenden crear más puestos de trabajo? La segunda de las modificaciones se centra en la definición de las causas organizativas, al considerarse tales también los cambios en el modo de organizar la producción.

Por otro lado, con la nueva redacción del artículo 51 del TRLET cambia radicalmente el procedimiento. Ya no es necesaria la autorización de la administración laboral (ERE extintivo) y se repite el esquema ya comentado al analizar las suspensiones de los contratos de trabajo (EREs suspensivos), añadiéndose ahora que «la autoridad laboral velará por la efectividad del período de consultas pudiendo remitir, en su caso, advertencias y recomendaciones a las partes que no supondrán, en ningún caso, la paralización ni la suspensión del procedimiento». Igualmente, se mantiene, en sintonía con la regulación anterior, la posibilidad de que la autoridad laboral impugne «los acuerdos adoptados en el período de consultas cuando estime que éstos se han alcanzado mediante fraude,

${ }^{52}$ Definiciones que no sirven para justificar que la empresa deje de obtener los suficientes beneficios como para mantener puestos de trabajo. 
dolo, coacción o abuso de derecho». En suma, puede concluirse que la eliminación de las facultades de control de la autoridad laboral (el ERE en sí) en materia de despidos colectivos agiliza los trámites del despido, y conduce directamente su enjuiciamiento al orden jurisdiccional social ${ }^{53}$. Lo que sucede es que las definiciones excesivamente amplias de las razones que justifican la extinción, sin vincularlas a ninguna finalidad lo suficientemente clara como para que el juez valore el equilibrio que debería existir entre el despido y la situación de la empresa echa por tierra las virtudes de la agilidad del procedimiento.

Finalmente, la seguridad, en contraposición a la flexibilidad, se manifiesta en la obligación de «ofrecer a los trabajadores afectados un plan de recolocación externa a través de empresas de recolocación autorizadas $\rangle^{54}$, que se impone a las empresas que lleven a cabo un despido colectivo que afecte a más de 50 trabajadores.

(b) Despido objetivo (artículo 52 del TRLET): son dos las modificaciones que se introducen en esta materia. Por una parte, se apuesta, con claridad, por la obligación que corresponde al empresario de «ofrecer al trabajador un curso dirigido a facilitar la adaptación a las modificaciones operadas» (letra b). Por otra parte, respecto al absentismo se elimina el requisito del absentismo total de la plantilla (letra d).

(c) Improcedencia del despido (artículo 56 del TRLET): se simplifica la estructura de este artículo debido a que se ha eliminado el denominado «despido exprés» que se contenía en su apartado segundo, y que consistía en que el empresario podía reconocer automáticamente la improcedencia del despido, ofreciendo la indemnización legalmente establecida (depositándola en el Juzgado de lo Social a disposición del trabajador y poniéndolo en conocimiento de éste), con la ventaja añadida de que quedaba liberado del pago de los salarios de tramitación si procedía al depósito de la indemnización en el plazo de 48 horas siguientes al despido. En principio, la eliminación de esta posibilidad parece razonable, puesto que a través de la misma se ocultaban verdaderos despidos por causas económicas, sin necesidad de alegar y probar una causa cierta para la terminación del contrato de trabajo, con la ventaja de poder evitar el pago de los salarios de tramitación ${ }^{55}$. Sin embargo, el alcance de dicha eliminación puede quedar en papel mojado, al limitarse el pago de los salarios de tramitación a los supuestos en los que, tras la calificación de improcedente de un despido, el empresario opte por la readmisión (salvo que el despedido sea un representante legal de los trabajadores, pues en este caso, si dicho trabajador opta tanto por la in-

${ }^{53} \mathrm{Al}$ respecto véase Blasco Pellicer, A. La extinción del contrato de trabajo en el RDL 3/2012: aspectos sustantivos, procesales y de Seguridad Social. En VVAA. La reforma laboral en el Real Decreto-ley 3/2012. Valencia: Tirant lo Blanch, p. 194 y ss.

${ }^{54} \mathrm{Cfr}$. nueva redacción del artículo 51.10 del TRLET.

${ }^{55}$ Sobre el éxito entre los empresarios de la extinción descausalizada mediante el mecanismo del artículo 56.2 del TRLET véase Esteve SegarRa, A. El despido exprés. La limitación de los salarios de tramitación. Valencia: Tirant lo Blanch, 2011, pp. 16-20. 
demnización como si lo hace por la readmisión, tendrá derecho a los salarios de tramitación ${ }^{56}$. La polémica está servida con esta medida de no abonar los salarios de tramitación cuando el empresario opte por no readmitir a los trabajadores despidos. De hecho, se ha planteado una cuestión de inconstitucionalidad al respecto $^{57}$, pese a que parte de la doctrina aboga por su constitucionalidad ${ }^{58}$.

Por otra parte, la indemnización por despido improcedente pasa a ser de 33 días por año trabajado, con el tope de 24 mensualidades, en lugar de los 45 días por año trabajado, con el topo de 42 mensualidades, que se preveía con anterioridad. Como se ha comentado anteriormente (supra 3.1), se generaliza expresamente lo que en la práctica ya venía practicándose tras la universalización subjetiva operada por el anterior Gobierno respecto al ámbito de aplicación del extinto contrato para el fomento de la contratación indefinida $^{59}$.

\subsection{Fondo de Garantía Salarial}

Tras la reforma se modifica el criterio por el que hasta ahora el FOGASA se hacía cargo de parte de los costes de los despidos por causas económicas. A partir de ahora asumirá el pago de 8 días de salario por año de servicio en los supuestos de despidos colectivos y objetivos procedentes en empresas de menos de 25 trabajadores, pero solamente respecto a los contratos indefini$\operatorname{dos}^{60}$.

${ }^{56}$ Cfr. nueva redacción de los apartados 2 y 4 del artículo 56 del TRLET.

${ }^{57}$ Vid. Auto del Juzgado de lo Social núm. 30 de Madrid, de 16 de abril de 2012 (rec. $161 / 2012)$.

${ }^{58}$ Véase Sempere NaVArRo, A. V. La eliminación de los salarios de tramitación y su ajuste constitucional (2002 y 2012). En Revista Aranzadi Doctrinal, 2012, núm. 2. (BIB 2012\622).

${ }^{59}$ Para el cálculo de las indemnizaciones por despidos improcedentes posteriores a la reforma realizada por el Real Decreto-ley 3/2012 pero que afectan a personas contratadas con anterioridad a dicha reforma debe tenerse en cuenta lo dispuesto por la Disposición Transitoria 5 de dicha norma.

${ }^{60} \mathrm{Cfr}$. nueva redacción del artículo 33.8 del TRLET. 